\title{
Stability Analysis of Neuro-Adaptive SMC-Based Current Sharing Technique for Multiphase Converters in Battery Charging Applications
}

\author{
Kamalesh MS ${ }^{1}$ \\ Department of EEE \\ Kongu Engineering \\ College \\ Tamilnadu, India \\ kamaleshmeped@gmail.com
}

\author{
N.Senthilnathan ${ }^{2}$, \\ Department of EEE \\ Kongu Engineering \\ College \\ Tamilnadu, India \\ nsenthilnathan@gmail.com
}

\author{
C.Bharatiraja ${ }^{3}$ \\ Department of EEE \\ SRM Institute of Science \\ and Technology \\ Tamilnadu, India \\ bharatiraja@gmail.com
}

\author{
Ahmed Zobaa ${ }^{4}$ \\ Department of ECE \\ College of Engineering \\ Brunel University \\ London, UK \\ ahmed.zobaa@brunel.ac.uk
}

\author{
Telles.B.Lazzarin 5 \\ Department of EE \\ Federal University of \\ Santa Catarina \\ Florianopolis, Brazil \\ telles@inep.ufsc.br
}

\author{
Mohd Tariq \\ Department of EE \\ Aligarh Muslim \\ University \\ Aligarh, India \\ tariq.ee@zhcet.ac.in
}

Abstract: In the present scenario, battery plays a vital role in most of the domestic and industrial applications as an uninterrupted power source for sensitive loads, storage systems, electric vehicles, etc. Conventional single port chargers are upgraded to multiport circuits in most of the battery charger applications. However, it faces the following problems; 1 . Insufficient control over the voltage regulated and current shared among the multiport converters, 2. Transient perturbation and stability control. This paper presents a new hybrid control strategy for an integrated renewable energy load bus. It comprises of Photovoltaic (PV) and Fuel Cell (FC) based source side converters delivering power to the battery chargers connected on the load side. The hybrid control strategy includes; 1. Neural Network (NN) based self-adapting Proportional -Integral (PI) tuner for adjusting the droop resistance values in multiport network and current sharing among the converters, 2 . Sliding Mode Controller (SMC) based PWM control for increased voltage regulation with constant current control as well. The hand in hand process of Neuro Adaptive Droop (NAD) - SMC takes care of the proper load sharing, battery charging and a rapid response control system with wide stable region. The proposed self-adapting and self-tracking technique is evaluated in Matlab/Simulink platform and the results were validated in real time prototypical hardware by implementing the control law using dSPACEMicrolabBox-1202.

Keywords - Boost converter, Sliding mode controller (SMC), current sharing, neuro-adaptive PI, droop resistance, autonomous control.

$\begin{array}{cl}\text { Nomenclature } \\ I_{L} & \text { Inductor Current } \\ V_{c} & \text { Capacitor Voltage } \\ D & \text { Duty cycle } \\ I_{z} & \text { Input current disturbance } \\ R_{0} & \text { Individual converter output resistance } \\ R_{\text {Load }} & \text { Load Resistance } \\ e_{v}(t) & \text { Error in voltage } \\ e_{I}(t) & \text { Error in current } \\ u_{v}(t) & \text { Voltage control signal } \\ u_{I}(t) & \text { Current control signal } \\ R_{d r o o p} & \text { Droop resistance } \\ K_{p} K_{i} & \text { PI gain of voltage control loop } \\ K_{p} K_{i}^{\prime} & \text { PI gain of current control loop } \\ I_{C 1,2} & \text { Circulating current } \\ e_{i n j} & \text { Input to the hidden layer of NN } \\ y_{\text {ink }} & \text { Input to the output layer of NN } \\ y_{k} & \text { Output of NN }\end{array}$

\section{INTRODUCTION}

In the current scenario, the electricity consumers are in need of DC power supply to their equipment's, motor loads, gadgets, electric vehicles, etc. One of the ultimate assets of energy storage is the battery, which plays an extreme role in electric vehicle applications. Implementation and maintenance of on road charging stations are the trending topics in the global energy market. Although, some ideologies like battery charging stations, battery swapping stations and fast charging stations are currently available, they have not yet spread widely among the consumers[1]. The reason behind this is lack of awareness among the common people, unavailability of charging stations at remote places, subsidiary requirement from the government, etc. Among the list, the unavailability of charging places at remote places makes the researcher to render the support from renewable sources like PV, FC and wind. Depending on the energy availability, they may be used all alone or may be in a combined hybrid manner. Pertaining to the hybridisation, more than one source converters are connected in parallel to the common load bus. The development of parallel converters to share the load and its control strategy remains prominent. The parallel converter requires; (i) voltage control among parallel converters (ii) load current sharing (iii) zero circulating current, (iv) self-regulating strategy during transient conditions [2]. Many current sharing methods like droop sharing, booster array, master slave, synchronous method, adaptive droop technique, droop index method were proposed in the literature [3-8]. The problems in existing methodologies are the gain values of the PI controllers are fixed, which fails the controller in responding to the sudden perturbations. Moreover, PI controllers are used to perform the PWM control and the droop resistance control as well; this makes the controller to hurdle up with one-on-one troublesome in quick convergence. Hence, this paper proposes a hybrid controller, which is designed in a loopin-loop approach such that, the existing problems are addressed effectively.

The first and foremost plan of action is to design an appropriate control law for SMC to administer the PWM adjustments for the boost converter. On behalf of the SMC based boost converter; passive SMC described in [9] derives the small signal model of the system. Most of the nonlinear systems with transient dynamics are easily analyzed and controlled by small signal modelling. Besides it, two loop digital SMC [10], PWM based adaptive SMC [11], hysteresis SMC [12], hyperplane SMC [13], trajectory based SMC [14] are some of 


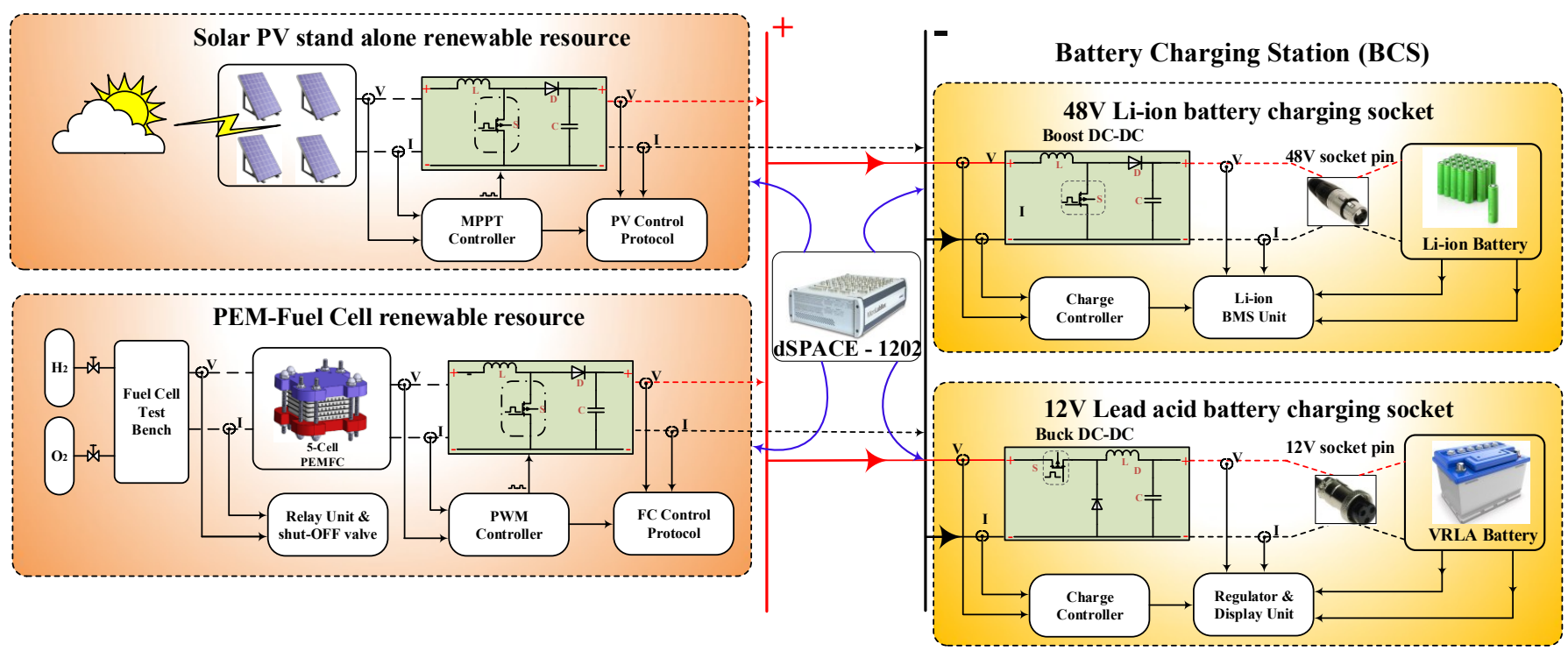

Fig. 1 Schematic Block diagram of the proposed multiphase charging circuit

Table I Nomenclature of the converters

\begin{tabular}{|c|c|c|c|c|c|c|c|c|}
\hline Parameters & \multicolumn{2}{|c|}{ Solar PV } & \multicolumn{2}{|c|}{ Fuel cell } & \multicolumn{2}{|c|}{ Li-ion Battery } & \multicolumn{2}{|c|}{ Lead Acid Battery } \\
\hline \multirow{3}{*}{$\begin{array}{c}\text { Voltage, } \\
\text { Current } \\
\text { and Power }\end{array}$} & $\mathrm{V}_{\mathrm{PV}}$ & $18.6 \mathrm{~V}$ & $\mathrm{~V}_{\mathrm{FC}}$ & $9.5 \mathrm{~V}$ & $\mathrm{~V}_{\mathrm{Li}}$ & $48 \mathrm{~V}$ & \begin{tabular}{l|l}
$\mathrm{V}_{\mathrm{BT}}$ & \\
\end{tabular} & $12 \mathrm{~V}$ \\
\hline & $\mathrm{I}_{\mathrm{PV}}$ & $8.1 \mathrm{~A}$ & $\mathrm{I}_{\mathrm{FC}}$ & $16.8 \mathrm{~A}$ & $\mathrm{I}_{\mathrm{Li}}$ & $1.1 \mathrm{~A}-2.1 \mathrm{~A}$ & $\mathrm{I}_{\mathrm{BT}}$ & $1.2 \mathrm{~A}-2.2 \mathrm{~A}$ \\
\hline & $\mathrm{P}_{\mathrm{PV}}$ & $\begin{array}{c}150 W^{*} 4 \\
\text { No's }\end{array}$ & $\mathrm{P}_{\mathrm{FC}}$ & $160 \mathrm{~W}$ & Capacity & $11 \mathrm{Ah}$ & Capacity & $12 \mathrm{Ah}$ \\
\hline \multirow{5}{*}{$\begin{array}{c}\text { Converter } \\
\text { parameters }\end{array}$} & \multicolumn{2}{|c|}{ DC-DC Boost Converter } & \multicolumn{2}{|c|}{ DC-DC Boost Converter } & \multicolumn{2}{|c|}{ DC-DC Boost Converter } & \multicolumn{2}{|c|}{ DC-DC Buck Converter } \\
\hline & Output voltage & $\mathrm{V}_{\mathrm{DC} 1}$ & Output voltage & $\mathrm{V}_{\mathrm{DC} 2}$ & Output voltage & $\mathrm{V}_{\mathrm{DC} 3}$ & Output voltage & $\mathrm{V}_{\mathrm{DC} 4}$ \\
\hline & Output current & $\mathrm{I}_{\mathrm{DC} 1}$ & Output current & $\mathrm{I}_{\mathrm{DC} 2}$ & Output current & $\mathrm{I}_{\mathrm{DC} 3}$ & Output current & $\mathrm{I}_{\mathrm{DC} 4}$ \\
\hline & Reference voltage & $\mathrm{V}_{\mathrm{DC} 1}$ & Reference voltage & $\mathrm{V}_{\mathrm{DC} 2}$ & Reference voltage & $\mathrm{V}_{\mathrm{DC} 3}$ & Reference voltage & $\mathrm{V}_{\mathrm{DC} 4}$ \\
\hline & Reference current & $\mathrm{I}_{\mathrm{DC} 1}$ & Reference current & $\mathrm{I}_{\mathrm{DC} 2}$ & Reference current & $\mathrm{I}_{\mathrm{DC} 3}$ & Reference current & $\mathrm{I}_{\mathrm{DC} 4}$ \\
\hline
\end{tabular}

the significant contribution of controlling the PWM of the boost converter with its state variables. The theoretical existence of sliding mode and its stability on the sliding plane is analyzed in [15] [16]. In this paper, a trajectory based SMC is utilized to handle the PWM, by using the state variables of the boost converter. A closed loop transfer function is derived and with the required voltage and current reference values, the error values are tracked and bounded within the rated limits and converge it to equilibrium.

With the aim of receiving the reference voltage for the SMC, the NN takes the role of reference estimator by adjusting the droop resistance. That is, NN adjusts the droop resistance value, which in turn adjusts the reference voltage of the individual converter, and its respective mathematical expressions will be derived in the forthcoming sections. Also, the total load current magnitude is monitored and controlled. Some of the NN techniques like nested order NN [17], approximation techniques, adaptive current control with $\mathrm{NN}$ [18], and self-tuning PI with adaptive NN [19] are elaborated in the literature. Similarly, some of the fast and integrated charging techniques are discussed in $[20,21]$

This paper considers an integrated DC power system having boost converters connected in parallel on the source side and the load side as well. The source side converters convert the source voltage to the load bus voltage and load side converter act as the charging circuit for the battery chargers. The paper handouts the following contributions:
1. Integration of renewable sources to supply the battery charging circuits specifically to stand alone charging stations.

2. A Centralized neuro adaptive controller is designed to update the droop resistance and to adjust the reference values for the individual parallel converters.

3. Devised an SMC with hyperbolic sliding surface to control the PWM of the switches in the converter.

The rest of the paper is organized in the following pattern: Section II describes the complete proposed model with NAD-SMC, Section III presents the ideology of SMC based PWM control and its respective control law is derived, Section IV derives the expression for NN based droop adjustments and Section V discuss the results of the proposed model.

\section{MULTIPHASE CONVERTERS MODELLING}

A hybrid integrated renewable sources like PV and FC are connected to a common load bus, in which battery charging circuits are connected as the load. The output voltage of the solar PV and FC are managed and linked to a standard $24 \mathrm{~V}$ DC voltage bus via a regulated DC-DC boost converter. These two renewable source side converters are accompanied with MPPT controller for PV and a gas valve control for FC. On the other hand in the load side, the battery charging circuits are connected through a boost or buck converter depending on the requirements. In this paper, both buck and boost conversion are considered. A $24 \mathrm{~V}$ to $48 \mathrm{~V}$ boost conversion ratio is considered for a $48 \mathrm{~V} /$ 
$11 \mathrm{Ah}$ Li-Ion battery and a $24 \mathrm{~V}$ to $12 \mathrm{~V}$ buck conversion ratio is considered for a $12 \mathrm{~V} / 12 \mathrm{Ah}$ Lead acid battery. The schematic block diagram of the proposed model is shown in Fig.1. The proposed work addresses the problem of sharing the high amplitude battery charging current with a Neurobased Self-Adaptive (NSA)-PI controller for current sharing and setting up the converter reference voltage by controlling the droop resistance value. Similarly, the role of SMC is to control the PWM for the converters on both the side (source and load side as well). The proposed work will accomplish the following steps to fulfil the above mentioned objectives:

Step: 1 The source side boost converters voltage and current $\left(\mathrm{V}_{\mathrm{DC} 1}, \mathrm{I}_{\mathrm{DC} 1}, \mathrm{~V}_{\mathrm{DC} 2}\right.$ and $\left.\mathrm{I}_{\mathrm{DC} 2}\right)$ are sensed by voltage and current sensors respectively. The sensed signals are conditioned by signal conditioning units and they are sent to ADC of dSPACE-1202 Control Panel (CLP) and they are monitored in ControlDesk Platform (CDP).

Step: 2 The load bus with a capacity of $24 \mathrm{~V} / 750$ watts will be delivering energy to the battery charging circuit(s), the charge controllers will be controlling the charging and discharging pattern of the battery via the $\mathrm{SOC}$ and $\mathrm{SOH}$ parameters. The load bus is capable of withstanding 31A, but the battery charging circuits may consume from $1.5 \mathrm{~A}$ to $5 \mathrm{~A}$ as the charging current, depending on the type of charging adapter.

Step: 3 The state of battery charging current requirement and the ongoing load current delivered by the battery are sensed and the estimated values are communicated to dSPACE-CLP as a digital input through (DIGITAL_IN).

Step: 4 From the data received in step. 2 and step.3, SMC will take care of controlling the PWM in all the converters connected to the bus. This is done by controlling the stability between the source side converters and the load side converters by adjusting the duty cycle on two switching states.

Step: 5 From the data received in step.1, NSA-PI controller will take care of controlling the voltage regulation in converter- 1 and converter- 2 by adjusting the $R_{\text {droop }}$ values, such that it reduces the magnitude of circulating current.

Step: 6 SMC will acknowledge for the stability within the threshold range to the master controller. In case of load change, the dynamics will be disturbed for a while and again it will be retained by SMC in a rapid time, and the steps will continue for next iteration. The detailed version of the control strategy is discussed in the following sections.

\section{CONTROL STRATEGY}

This section describes the methodology of the proposed NAD-SMC hybrid control strategy. As far as this paper, concerns only on the source side converters for delivering the rated power to the load bus by estimating the availability of power from PV and FC. It is to be noted that, PV power is fully utilized during the day time and the power extraction from FC is adopted only if its service is required. In the control process, a closed loop transfer function of the boost converter with state variables including parasitic components is derived. It is followed by a mathematical derivation of control law to adjust the PWM dynamically and finally, a neural structure with droop resistance expression as the objective function is formulated and linked to the control process.

\section{A. Small Signal Model}

The mathematical model of the boost converter with state variables, inductor current as $x_{1}$ and capacitor voltage as $x_{2}$ and the respective state equations can be given as follows,

$$
\begin{gathered}
\dot{x}_{1}=\frac{1}{L}\left[V_{\text {in }}-(1-D) x_{2}\right] \\
\dot{x}_{2}=\frac{1}{C}\left[(1-D) x_{1}-I_{\text {Load }}\right]
\end{gathered}
$$

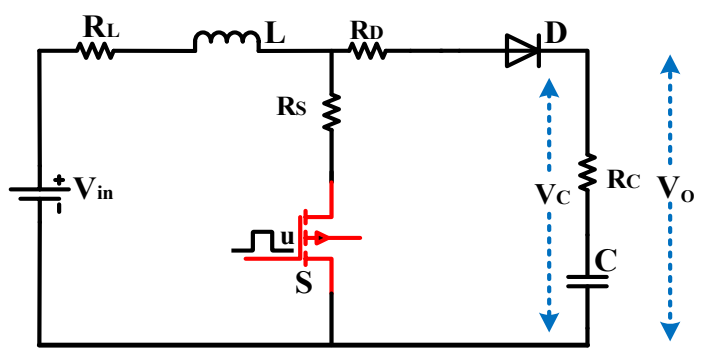

Fig. 2. Boost converter including parasitic components

On substitution and simplifying the circuit components, the state and output equations of the averaged large signal are given as,

$$
\begin{gathered}
{\left[\begin{array}{l}
I_{L} \\
V_{C}
\end{array}\right]=\left[\begin{array}{cc}
0 & \frac{-(1-D)}{L} \\
\left(\frac{1-D}{C}\right) & \frac{-1}{R_{0} C}
\end{array}\right]\left[\begin{array}{l}
I_{L} \\
V_{C}
\end{array}\right]+\left[\begin{array}{l}
\frac{1}{L} \\
0
\end{array}\right]\left[V_{i n}\right]} \\
+\left[\begin{array}{c}
0 \\
\frac{-1}{C}
\end{array}\right]\left[I_{z}\right] \\
{\left[\begin{array}{c}
V_{0} \\
I_{i n}
\end{array}\right]=\left[\begin{array}{ll}
0 & 1 \\
1 & 0
\end{array}\right]\left[\begin{array}{l}
I_{L} \\
V_{C}
\end{array}\right]}
\end{gathered}
$$

In equilibrium condition (i.e.) $0=\dot{x}=A x+B u$, the steady state output $V_{0}$ can be derived as,

$$
V_{0}=-\left[\begin{array}{ll}
0 & 1
\end{array}\right]\left[\begin{array}{cc}
\frac{-L}{R_{0}(1-D)^{2}} & \frac{C}{1-D} \\
\frac{-L}{1-D} & 0
\end{array}\right]\left[\begin{array}{l}
\frac{1}{L} \\
0
\end{array}\right] V_{i n}
$$

On multiplying and rearranging the above equation,

$$
\frac{V_{0}}{V_{\text {in }}}=\frac{1}{1-D}
$$

In-order to achieve the small signal model of the system $(\hat{x})$, the steady state quantities have to be subtracted from its averaged large signal model like,

$$
\begin{array}{r}
\hat{d}=D-d ; \hat{v}_{0}=V_{0}-v_{0} ; \hat{v}_{i n}=V_{i n}-v_{i n} ; \hat{\imath}_{z} \\
=I_{z}-i_{z} ; \hat{\imath}_{L}=I_{L}-i_{L}
\end{array}
$$

Applying (7) in (3-5) derives the final small signal expression of the state equation and it takes the form as,

$$
\begin{aligned}
{\left[\begin{array}{l}
\hat{I}_{L} \\
\hat{v}_{C}
\end{array}\right]=\left[\begin{array}{cc}
0 & \frac{-(1-D)}{L} \\
\frac{(1-D)}{C} & \frac{-1}{R_{0} C}
\end{array}\right]\left[\begin{array}{l}
\hat{I}_{L} \\
\hat{v}_{C}
\end{array}\right]+\left[\begin{array}{l}
\frac{1}{L} \\
0
\end{array}\right]\left[\hat{v}_{i n}\right] } \\
+\left[\begin{array}{c}
0 \\
\frac{-1}{C}
\end{array}\right]\left[\hat{\imath}_{z}\right]+\left[\begin{array}{c}
\frac{V_{c}}{L} \\
\frac{I_{L}}{C}
\end{array}\right][\hat{d}]
\end{aligned}
$$


The transfer function expression for the individual boost converter is given in (9). If the values of $V_{\text {in }}, L$ and $R_{L}$ changes, then the individual converter transfer function also gets varied.

$$
\begin{aligned}
& G_{v}(s)=\frac{R_{\text {Load }}\left(1+R_{C} \mathrm{~s}\right)}{\mathrm{s}^{2}\left(R_{\text {Load }}+R_{L}\right) L \mathrm{C}+\mathrm{s} .\left(\mathrm{L}+R_{\text {Load }} \cdot R_{C}\right)+R_{\text {Load }}} \\
& \times V_{\text {in }} \\
& G_{I}(\mathrm{~s})=\frac{R_{L} R_{C} s}{\mathrm{~s}^{2}\left(R_{C}+R_{L}\right) L+\mathrm{s} .\left(\mathrm{C}+R_{L} \cdot R_{C}\right)+R_{\text {Load }}} \times \frac{2 L I_{L}}{V_{\text {in }}}
\end{aligned}
$$

The above transfer function will be employed in closed loop operation with the inclusion of closed loop gain. Also, they are used by SMC in voltage regulation.

\section{B. Sliding mode control of PWM}

SMC controls the duty cycle of the individual boost converters by handling the errors on the sliding surface $(\sigma)$.

$$
\sigma=K_{1}\left(V_{D C 1}-V_{\text {Load }}{ }^{*}\right)+K_{2}\left(V_{D C 2}-V_{\text {Load }}{ }^{*}\right)
$$

Where, $K_{1}$ and $K_{2}$ are the positive real sliding constant values. Here, the load voltage depends on the load current and load drop, which is given as $V_{\text {Load }}=I_{\text {Load }} * R_{\text {Load }}$.

Where, $I_{\text {Load }}{ }^{*}=\frac{V_{\text {Load }}{ }^{*}}{R_{\text {Load }}} * I_{\text {Load }}$

The error values in load voltage and individual converter voltage are calculated to commutate the sliding surface with respect to time.

$$
\begin{aligned}
& e_{v 1}(t)=V_{\text {Load }}(t)-V_{D C 1}(t) \\
& e_{v 2}(t)=V_{\text {Load }}(t)-V_{D C 2}(t)
\end{aligned}
$$

Hence, the sliding function is rewritten as,

$$
\sigma=K_{1} e_{v 1}(t)+K_{2} e_{v 2}(t)
$$

The state variables of the individual converters are changed as,

$$
\begin{aligned}
& \dot{x}_{1(\text { new })}=\frac{1}{L_{1}}\left[V_{\text {in }}-\left(1-D_{1}\right)\left(V_{\text {Load }}(t)+e_{v 1}(t)\right)\right] \\
& \dot{x}_{1(\text { new })}=\frac{1}{L_{2}}\left[V_{\text {in }}-\left(1-D_{2}\right)\left(V_{\text {Load }}(t)+e_{v 2}(t)\right)\right]
\end{aligned}
$$

Where, the suffix 1 and 2 indicates the converters 1 and 2 respectively,

Substituting (14) in (13),

$$
\dot{\sigma}=K_{1}{ }^{\prime} e_{v 1}^{\cdot}(t)+K_{2}{ }^{\prime} e_{v 2}^{\cdot}(t)
$$

The vector of the sliding surface constants are selected such that the sliding mode occurs around the desired reference point. Thus the existence condition $\operatorname{Lim}_{\sigma \rightarrow 0}$ of the sliding surface is given as,

$$
\sigma \dot{\sigma}=\left(K_{1}{ }^{\prime} e_{v 1}(t)+K_{2}{ }^{\prime} e_{v 2}(t)\right)\left(K_{1}{ }^{\prime} e_{v 1}(t)+K_{2}{ }^{\prime} e_{v 2}^{\cdot}(t)\right)=0
$$

This equation defines a sliding line moving through the origin. The zero voltage, zero current and their respective errors are represented in this axis. The sliding surface cleaves the sliding plane into two regions. In order to force the system to track the sliding surface, each area has a particular switching state.

$$
u=\left\{\begin{array}{cl}
1 \Leftrightarrow D^{+} & \text {if } \sigma(t)<0 \\
0 \Leftrightarrow D^{-} & \text {if } \sigma(t)>0
\end{array}\right\}
$$

Thus, the duty cycle gets incremented or decremented based on the control signal received from the SMC.

\section{Neuro adaptive droop resistance control}

Parallel connection of boost converter with NSA-PI droop control for current sharing is briefed in this sub-section, where the droop resistance values are updated with new values as per the load requirement; they follow a racing algorithm with that of the adaptive PI values. During the parallel operation, unequal voltages can cause circulating current $\left(I_{C 1,2}\right)$ between the converters and its general expression is given as,

$$
I_{C 1,2}=\frac{I_{D C 1}-I_{D C 2}}{2} \Leftrightarrow \sum_{j=2}^{n} \frac{I_{D C 1}-I_{D C j}}{n}
$$

Equal voltage in the circuit holds a zero circulating current which reduces the power loss and increases the efficiency of the system. The deviation in output voltage can be given as,

$$
\Delta V_{\text {Load }}=V_{\text {Load }}{ }^{*}-\left(I_{\text {Load }} * R_{\text {Load }}\right)
$$

The voltage deviation has to be adjusted in the load voltage reference value in (10) by the PI controller. Hence (18) is updated as the output from PI controller as a control signal,

$$
\begin{gathered}
u_{v}(t)=K_{p} \Delta V_{\text {Load }}+K_{i} \int \Delta V_{\text {Load }} \\
V_{\text {Load }}{ }^{*}{ }_{(\text {new })}=V_{\text {Load }}{ }^{*}+\Delta V_{\text {Load }}-\left(I_{\text {Load }} * R_{\text {Load }}\right)
\end{gathered}
$$

Similarly, the same is followed for the load current,

$$
\begin{gathered}
u_{I}(t)=K_{p}{ }^{\prime} \Delta I_{\text {Load }}+K_{i}{ }^{\prime} \int \Delta I_{\text {Load }} \\
V_{\text {Load }}{ }^{*}{ }_{\text {(new })}=V_{\text {Load }}{ }^{*}+\Delta V_{\text {Load }}-\left(\left(I_{\text {Load }}+\Delta I_{\text {Load }}\right) * R_{\text {Load }}\right)
\end{gathered}
$$

The value of $K_{p}, K_{i}, K_{p}{ }^{\prime}$ and $K_{i}{ }^{\prime}$ are updated by the adaptive neural network algorithm given below,

BPN - Algorithm: $N N$-Adaptive PI control
Input: Discrete error in voltage and current $\left(e_{v}(n) \& e_{I}(n)\right.$
Output: Change in PI value $\Delta K_{p}, \Delta K_{i}, \Delta K_{p}{ }^{\prime}$ and $\Delta K_{i}{ }^{\prime}$
Data: Testing target set of $K_{p} \& K_{i}-K_{p}{ }^{\prime} \& K_{i}{ }^{\prime}$
Input to hidden layer: $e_{i n j}=b_{0 j}+\sum_{j} e_{v}(n) \cdot b_{i j}$
Input to output layer: $y_{i n k}=w_{0 j}+\sum_{k} e_{i n j}(n) \cdot w_{i j}$
Error Correction:
\[ \delta_{k}=\left(t_{k}-y_{k}\right) f^{\prime}\left(y_{i n k}\right) \Rightarrow \text { Weight correction } \]
\[ \delta_{j}=b_{i j} f^{\prime}\left(e_{i n j}\right) \Rightarrow \text { Bias correction } \]

Update:

Change in weight $\Delta w_{i j}=-\alpha \frac{\partial e_{v}(t)}{\partial w_{i j}}$

$$
\Delta w_{i j(n+1)}=-\alpha \frac{\partial e_{v}(t)}{\partial w_{i j}}+\eta \Delta w_{i j(n)}
$$

Change in bias $\Delta b_{i j}=\alpha \delta_{j} e_{v}(n)$

$$
b_{0 j}=b_{i j}+\Delta b_{i j}
$$

Output: Having bipolar activation function

\section{Decision:}

$$
y_{k}=f\left(y_{\text {ink }}\right)=\frac{1}{1+e^{-y_{\text {ink }}}}
$$

$$
y_{k}=\left\{\begin{array}{c}
+1 \Longrightarrow \Delta K_{p}=+0.05 * K_{p} \text { and } \Delta K_{i}=+0.05 * K_{i} \\
0 \Longrightarrow \text { No change in } \Delta K_{p} \text { and } \Delta K_{i} \\
-1 \Longrightarrow \Delta K_{p}=-0.05 * K_{p} \text { and } \Delta K_{i}=-0.05 * K_{i}
\end{array}\right\}
$$

From the above algorithm's decision, the updated PI controller gains of the respective voltage and current in (19) and (20) are used to adjust the reference voltage to the individual converters by adjusting the droop resistance, and it is given as, 


$$
R_{\text {droop }^{*}{ }_{(\text {new })}}=R_{\text {droop }_{(\text {old })}} \pm \frac{{V_{\text {Load }}}^{*}{ }_{\text {(new) }}}{I_{\text {Load }}}
$$

The $R_{\text {droop }}$ has to be adjusted and take a new value when the load dynamics comes into action. This process of instantaneous renewal is shown in Fig.3.

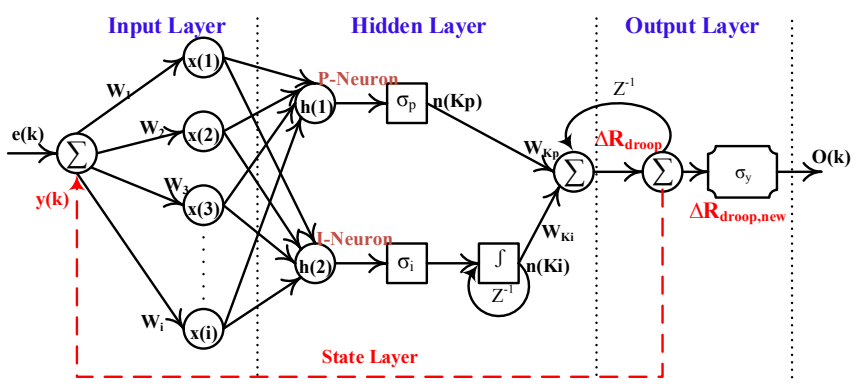

Fig.3 Adaptive Neural based PI for droop adjustments
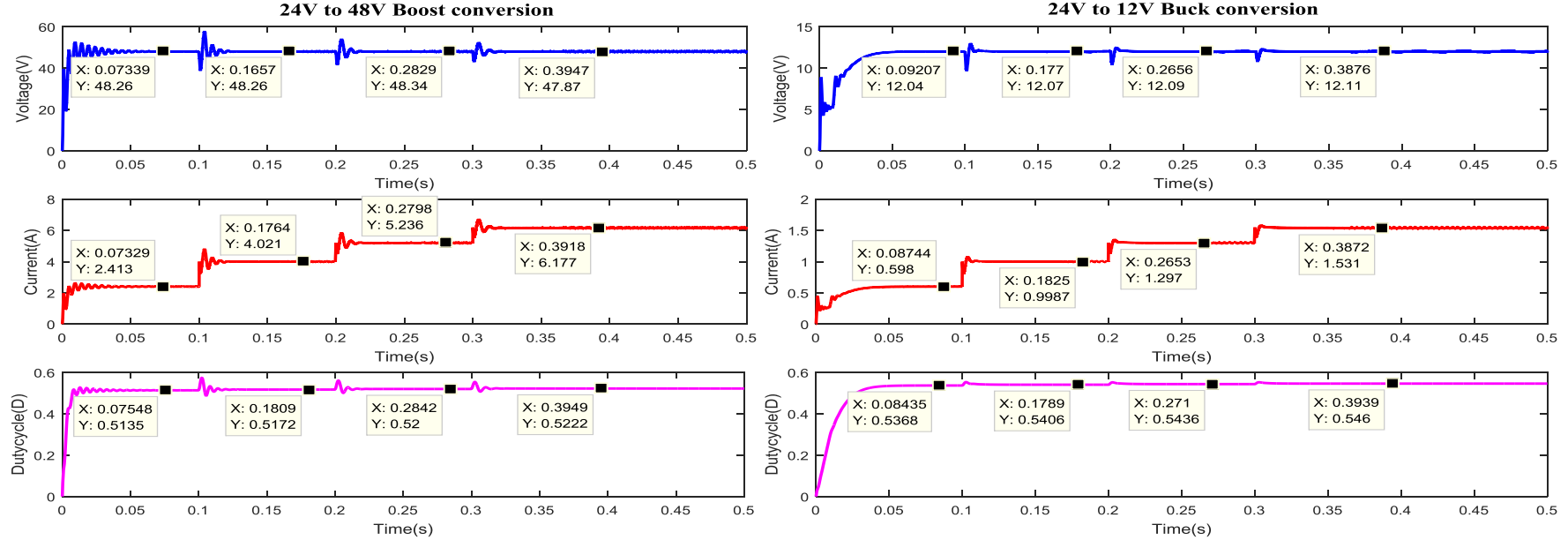

Fig. 4.a V-I curves at load side converter during transients
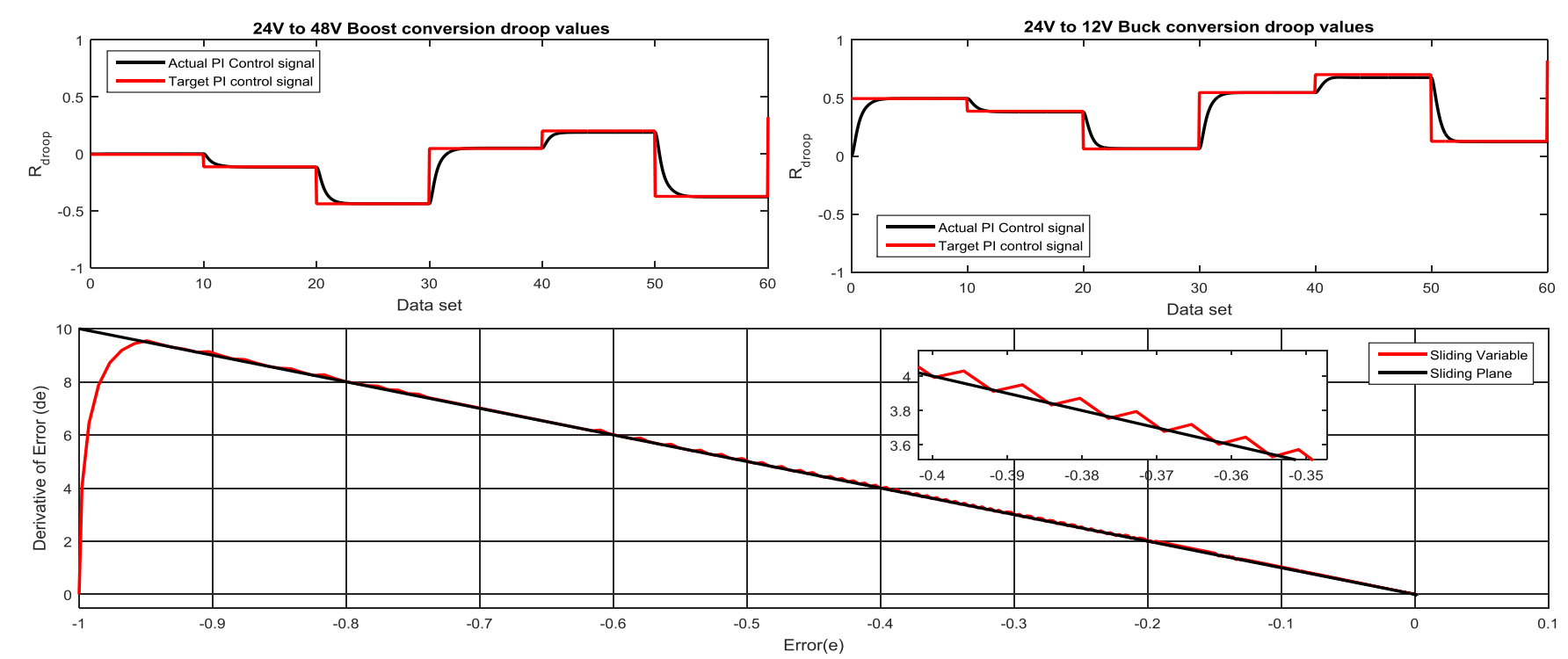

Fig. 4.b V-I curves at load side converter during transients
This section analyses the stability of the proposed model and validates the responses with simulation results. As per the schematic shown in Fig.1, the circuits are configured and the respective sensor connections are given to the dSPACE-CLP. By following steps discussed in the Section.II, multiphase topology is controlled in the dSPACE-CDP. The neural network algorithm elaborated in Section.III-c will be running at the back end in estimating the PI gains. The proposed model is tested for its stability under various loading conditions, as the battery charge controller may extract different charging current depending on the BMS. The performance of NN in controlling the duty cycle and maintaining the constant voltage under dynamic situation shows better performance. The load resistance values are dynamically changed at $0.1 \mathrm{~s}, 0.2 \mathrm{~s}$ and $0.3 \mathrm{~s}$ and its respective variations are captured and its convergence speed for recovering to the stable state is shown in Fig.4.a. Similarly, the performance of NN in tracking the droop

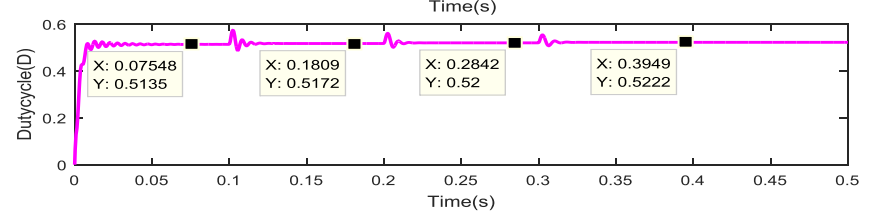


resistance value for adjusting the reference voltage to the SMC subsystem is shown in Fig.4.b.
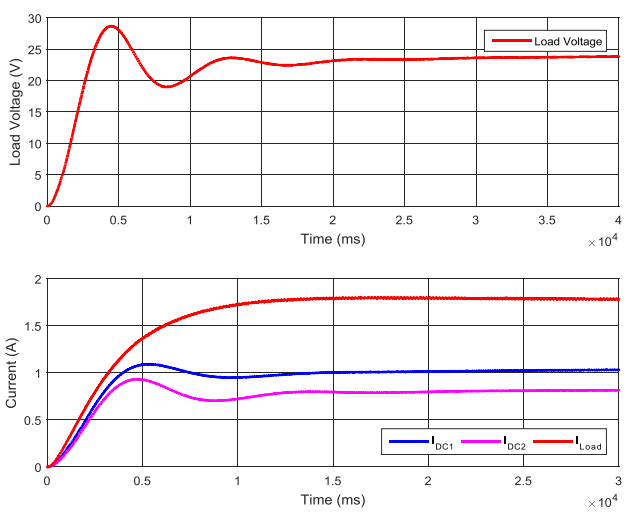

Fig. 5 Load bus voltage and current sharing

The target data sets for the NN training are created with various test cases and the respective gain values are loaded as a data set. The actual values of the PI gain with respect to the $R_{\text {droop }}$ attains the target in a rapid computation. On the other hand, the stability of the SMC sliding on the sliding plane reaches the equilibrium in a quick convergence. Fig. 5 shows the load bus voltage of $24 \mathrm{~V}$ and the total load current of $1.75 \mathrm{~A}$ is shared by the PV converter about $1 \mathrm{~A}$ and the FC converter about $0.75 \mathrm{~A}$.

The above shown results, validates the performance of the proposed model on par with the stability, voltage regulation and current sharing under various dynamic conditions.

\section{CONCLUSION}

This paper has implemented the NN-SMC control strategy for controlling the voltage regulation and proper current sharing, with the mitigation of circulating current nearer to zero in a rapid time. Simulation results justify the excellent convergence of the stability between the converters with good voltage regulation. On concerning the simulation results, NADSMC technique performs in an excellent manner to support the load in both boosting and bucking conversion process. Similarly, in simulation analysis the controller takes $0.1 \mathrm{~s}$ to reach the reference voltage level, hence this justifies that the circulating current reaches zero or near to zero. However, in experimental results, few microamperes of circulating current are present during the night time and especially when the power is suddenly supplied to the battery. The usage of SIL / HIL testing of the proposed model using dSPACE can be escalated in any BCS or FCS, with an automated indigenous integrated microcontroller.

\section{REFERENCES}

[1] Z. Xian and G. Wang, "Optimal dispatch of electric vehicle batteries between battery swapping stations and charging stations," in 2016 IEEE Power and Energy Society General Meeting (PESGM), 2016, pp. 1-5.

[2] S. Augustine, M. K. Mishra, and N. Lakshminarasamma, "Adaptive Droop Control Strategy for Load Sharing and Circulating Current Minimization in Low-Voltage Standalone DC Microgrid," IEEE Transactions on Sustainable Energy, vol. 6, pp. 132-141, 2015.
[3] J. Harding, "Current Sharing Methods for DC-DC Converters in Parallel," ed. vicorpower: Vicorpower, Open article, p. 3.

[4] K. Jung-Won, C. Hang-Seok, and C. Bo Hyung, "A novel droop method for converter parallel operation," IEEE Transactions on Power Electronics, vol. 17, pp. 25-32, 2002.

[5] J. Wei and Z. Yu, "Load Sharing Techniques in Hybrid Power Systems for DC Micro-Grids," in 2011 Asia-Pacific Power and Energy Engineering Conference, 2011, pp. 1-4.

[6] S. Augustine, M. K. Mishra, and N. Lakshminarasamma, "Circulating current minimization and current sharing control of parallel boost converters based on Droop Index," in 2013 9th IEEE International Symposium on Diagnostics for Electric Machines, Power Electronics and Drives (SDEMPED), 2013, pp. 454-460.

[7] C. Li, J. Wu, K. Zhang, X. Dai, and S. Xu, "Improved droop control based voltage compensation and variable droop coefficient in DC microgrids," in 2016 UKACC 11th International Conference on Control (CONTROL), 2016, pp. 1-6.

[8] Kamalesh MS, Vikashini M, and Pradeep S, "Precompensated Master Slave Control of Parallel DC-DC Converter in DC-Microgrid," in 2018 International Conference on Current Trends Towards Converging Technologies (ICCTCT), 2018, pp. 1-5.

[9] L. C. Xiaoling YUAN, Xuchang WEI, "Control Strategy for Boost Converter based on Passive Sliding Control Mode," International federation of Automatic Control (IFAC) hosting by elsevier, vol. IFACPapers Online 48-28, pp. 134-137, 2015.

[10]E. Vidal-Idiarte, C. E. Carrejo, J. Calvente, and L. Martínez-Salamero, "Two-Loop Digital Sliding Mode Control of DC-DC Power Converters Based on Predictive Interpolation," IEEE Transactions on Industrial Electronics, vol. 58, pp. 2491-2501, 2011.

[11] S. Oucheriah and L. Guo, "PWM-Based Adaptive Sliding-Mode Control for Boost DC-DC Converters," IEEE Transactions on Industrial Electronics, vol. 60, pp. 3291-3294, 2013.

[12] O. Lopez-Santos, L. Martinez-Salamero, G. Garcia, H. Valderrama-Blavi, and T. Sierra-Polanco, "Robust Sliding-Mode Control Design for a Voltage Regulated Quadratic Boost Converter," IEEE Transactions on Power Electronics, vol. 30, pp. 2313-2327, 2015.

[13]M. Salimi, J. Soltani, A. Zakipour, and N. R. Abjadi, "Hyper-plane sliding mode control of the DC-DC buck/boost converter in continuous and discontinuous conduction modes of operation," IET Power Electronics, vol. 8, pp. 1473-1482, 2015.

[14]Kamalesh MS, Senthilnathan Nattuthurai, and Bharatiraja Chokkalingam, "Design of a Novel Boomerang Trajectory for Sliding Mode Controller," International Journal of Control, Automation and Systems, 2020/05/19 2020.

[15]S. Singh, D. Fulwani, and V. Kumar, "Robust sliding-mode control of $\mathrm{dc} / \mathrm{dc}$ boost converter feeding a constant power load," IET Power Electronics, vol. 8, pp. 1230-1237, 2015.

[16]M. Su, Z. Liu, Y. Sun, H. Han, and X. Hou, "Stability Analysis and Stabilization Methods of DC Microgrid With Multiple Parallel-Connected DC-DC Converters Loaded by CPLs," IEEE Transactions on Smart Grid, vol. 9, pp. 132-142, 2018.

[17]I. H. Kim and Y. I. Son, "Regulation of a DC/DC Boost Converter Under Parametric Uncertainty and Input Voltage Variation Using Nested Reduced-Order PI Observers," IEEE Transactions on Industrial Electronics, vol. 64, pp. 552-562, 2017.

[18]H. N. Tran, K. M. Le, and J. W. Jeon, "Adaptive Current Controller Based on Neural Network and Double Phase Compensator for a Stepper Motor," IEEE Transactions on Power Electronics, vol. 34, pp. 8092-8103, 2019.

[19] W. Gou-Jen, F. Chuan-Tzueng, and K. J. Chang, "Neural-network-based self-tuning PI controller for precise motion control of PMAC motors," IEEE Transactions on Industrial Electronics, vol. 48, pp. 408-415, 2001.

[20]M. Sabarimuthu, N. Senthilnathan, M. A. Kumar, M. S. Kamalesh, V. Jayaprakash, and R. Srinivasan, "Fast and Integrated Chargers for Lithium Ion Batteries," IOP Conference Series: Materials Science and Engineering, vol. 937, p. 012004, 2020/10/02 2020.

[21] A. Khaligh and M. D. Antonio, "Global Trends in High-Power On-Board Chargers for Electric Vehicles," IEEE Transactions on Vehicular Technology, vol. 68, pp. 3306-3324, 2019. 